\title{
The Effect of Visual Stimulus on Voluntary Eye Movement Based on a VOR/OKR Model
}

\author{
Le Anh Son ${ }^{1)}$ Makoto Inagami $^{2)}$ Hiroto Hamada $^{\text {3) }}$ Tatsuya Suzuki ${ }^{4)}$ Hirofumi Aoki ${ }^{\text {) }}$ \\ 1) Graduate School of Engineering, Nagoya University \\ Furo-cho, Chikusa-ku, Nagoya, 464-8601,Japan(E-mail:leanhsonvn@gmail.com) \\ 2) Institute of Innovation for Future Society, Nagoya University \\ Furo-cho,Chikusa-ku, Nagoya, 464-8601,Japan (E-mail:inagami@coi.nagoya-u.ac.jp) \\ 3) Vehicle Engineering Division, Toyota Motor Corporation \\ 1, Toyota-cho, Toyota, Aichi, 471-8572, Japan (E-mail: hiroto hamada@mail.toyota.co.jp) \\ 4) Graduate School of Engineering, Nagoya University \\ Furo-cho, Chikusa-ku, Nagoya, 464-8601,Japan (E-mail: t suzuki@nuem.nagoya-u.ac.jp) \\ 5) Institute of Innovation for Future Society, Nagoya University \\ Furo-cho, Chikusa-ku, Nagoya, 464-8601,Japan (E-mail: hiro.aoki@,nagoya-u.jp)
}

Received on June 14, 2016

Presented at the JSAE Annual Congress on May 27, 2016

\begin{abstract}
The main purpose of this study is to investigate the effect of visual stimulus on voluntary eye movement during driving. In this paper, we examine two cases: driving with/without visual stimulus by means of a driving simulator. We develop a model that consists of both vestibulo-ocular reflex (VOR) and optokinetic reflex (OKR) components. By comparing the observed eye movement and the simulation result of the model, the results of eye movement simulation was more accurate than VOR model only even in a naturalistic situation with optic flow of the visual scene and the driver's voluntary eye movement.
\end{abstract}

\section{KEY WORDS: Human engineering, Vestibulo-ocular reflex (VOR), Optokinetic reflex (OKR), Optic flow [C2]}

\section{INTRODUCTION}

Driving requires a complex skill that involves with the vehicle itself (e.g., speed control), other road users (i.e., other vehicles, cyclists, and pedestrians), road infrastructure, surrounding environment, and so on. During driving a vehicle on a road, visual cues are the main source to supply information to the brain as a sensor which leads to decision making. Besides, workload refers to demands imposed on human operator by a given task, and workload measurement involves an attempt to assess performance limitations of human. Therefore the eye movement plays a very important role and it can be used to estimate mental workload during driving as suggested by previous researches. Obinata et al. estimated the driver's mental workload from the difference between the measured eye movements and the eye simulation using a VOR model ${ }^{(1)}$.

To simulate the eye movement, several researchers used VOR models which can estimate the eye movement based on the head movement ${ }^{(2)(3)(4)(5)}$. In case of gazing one target, when the head turns to the left, the eyes move in the opposite direction to stabilize the visual world based on the input to the vestibular organ. This involuntary eye movement is called as the vestibuleocular reflex (VOR). The vestibular system, which is a sensory mechanism in the inner ear, provides the principal contribution to the sense of balance and spatial orientation. The system consists of two parts: the otoliths and the semicircular canal.

\subsection{Vestibulo-ocular reflex model}

Based on the previous researches, VOR model can be used to estimate the eye movement from the movement of the head. Among those researches, we used the VOR model proposed by Merfeld and Zupan ${ }^{(6)}$, which reflects interactions between the otoliths and the semicircular canals. In this model head movement is represented by a linear acceleration and an angular velocity as inputs, and the movement of the eyeball is the output $^{(4)}$. Details of the VOR model are shown in Figure 1.

This model has been used by previous researches to examine various aspects of driver behavior. For example, Omura et al. used the VOR model to determine the relationship between measured eye movements and subjective evaluations of simulated brake motion ${ }^{(7)}$. In their research, the passenger's comfort was measured by comparing the observed eye 
movement with that simulated by using the VOR model. The researchers found a tendency toward a relationship, but the number of subject was insufficient for the purpose of making a decision. In addition, their parameter identification by using a hybrid genetic algorithm left a gap between simulation and measurement. Obinata's group has also used the VOR model to evaluate mental workload ${ }^{(8)}$ and driver distraction in terms of memory-decision workload ${ }^{(9)}$. They presented a new method for quantifying mental workloads by utilizing the VOR. They did not, however, consider changes in gaze direction.

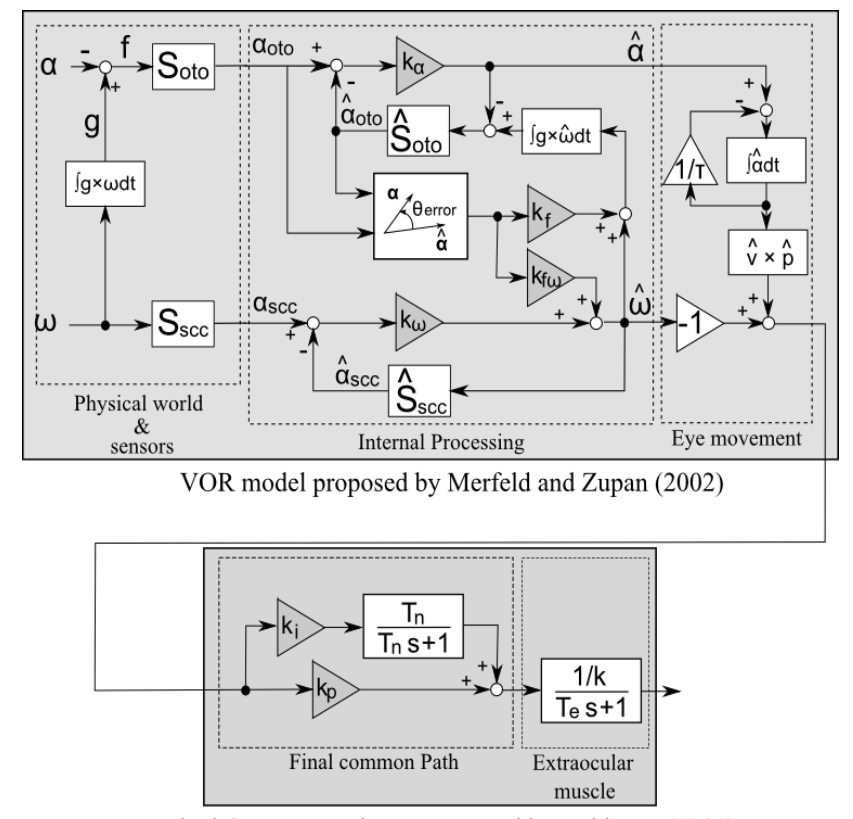

Final Common path part proposed by Robinson (1981)

Fig.1 VOR models developed by Obinata et al. ${ }^{(7)-(9)}$

\subsection{Optokinetic model}

According to Robinson ${ }^{(4)}$ and Schweigard \& Mergner ${ }^{(10)}$, on the visual scene, the eye movement simulation requires to combine actions of the vestibulo-ocular reflex (VOR; eye stabilization in space) and the optokinetic reflex (OKR; eye stabilization on the visual scene).

In most previous researches on the OKR-VOR interaction, passive and active head movements were used. The effect of active head rotation may be enhanced if the optokinetic input is modified by magnifying spectacles. By using active and passive head movements, Schweigard \& Mergner created the relationship between visual pattern motions in space with subject's head movements. Based on that information, the negative feedback loop was made to stabilize image on the retina and the VOR only as a useful addition which compensates for the limited bandwidth of the OKR during high frequency/velocity head rotations.
On another way, Newman ${ }^{(11)}$ and Clark et al. ${ }^{(12)(13)}$ dealt with the interaction between VOR and OKR by including static and dynamic visual sensory information from four independent visual sensors (visual velocity, position, angular velocity and gravity). The process of visual input is shown in Figure 2.

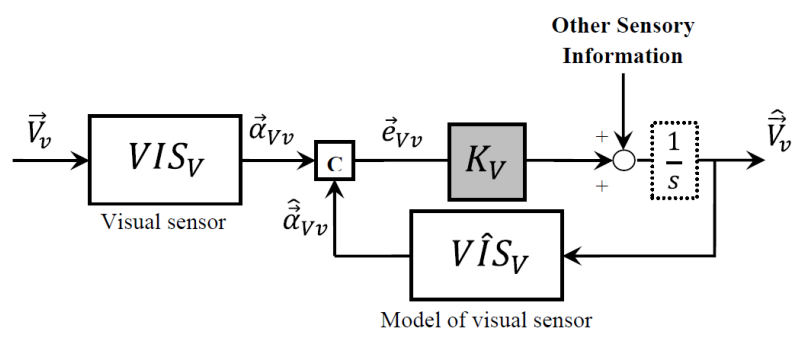

Fig.2. Generic visual model path way proposed by Newman

In the past, eye movements have been used for various applications in daily life ${ }^{(14)}$. In their research, the importance of the VOR - OKR interaction was pointed out. However, up until now, there is no research succeeding for combining VOR and OKR to simulate eye movement not only for daily life but also while driving. Since the visual information is important for driving as discussed above, we have to consider the OKR effect on eye movement simulation.

\section{METHOD}

To simulate driver's eye movement even in the natural traffic environment with optic flow of the visual scene and the driver's voluntary eye movement, the effect of optic flow from visual scene on eye simulation should be reduced. Hence, we conducted experiments in two cases: driving with/without visual stimulus by mean of a driving simulator. After that, the head movement was used to simulate eye movement by applying two kinds of models: only VOR model and both VOR and OKR models (Figure 3).

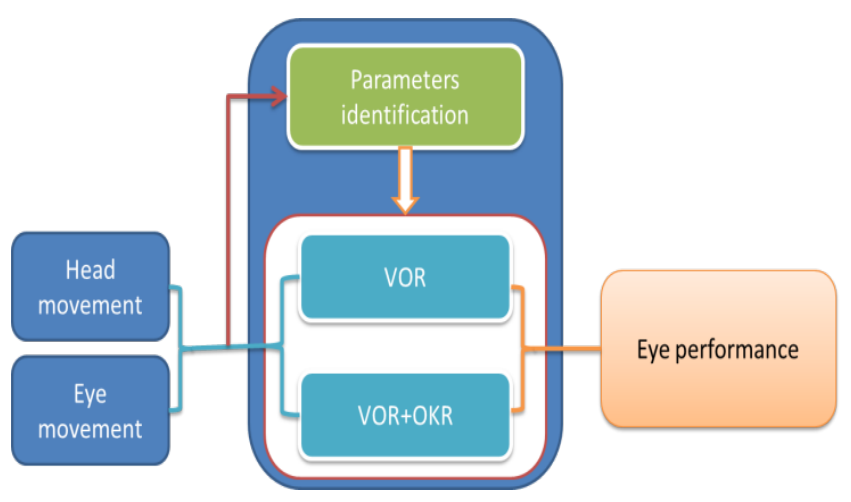

Fig.3 Overview of the research methodology 


\subsection{VOR model}

This study applied the VOR model proposed by Merfeld and Zupan was applied ${ }^{(6)}$ that considered the interaction between semicircular canal and otolith. The model detail is shown in Figure 4.

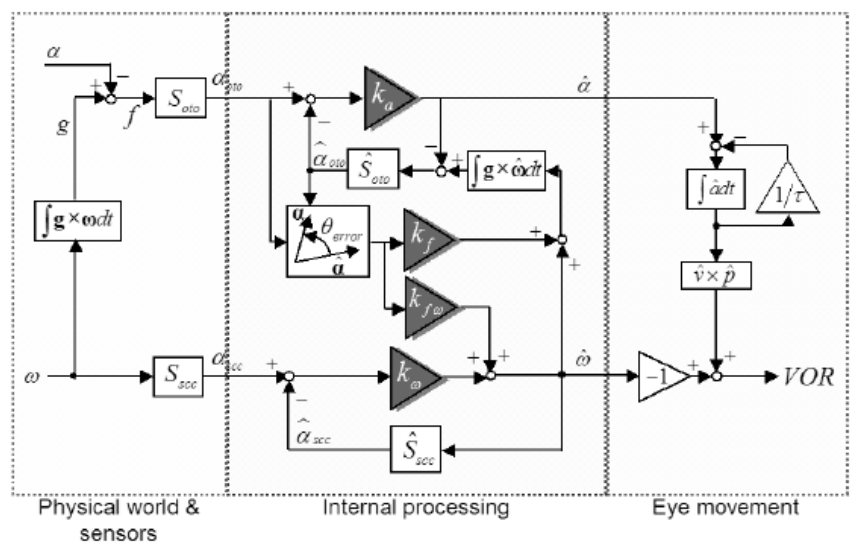

Fig.4. VOR model in MATLAB Simulink

In this model, linear acceleration $(\alpha)$ and angular velocity $(\omega)$ of head-fixed coordinator frame are the inputs. The orientation of gravity (g) with respect to the head is calculated using a quaternion integrator the angular velocity. The otolith is modeled to unify and respond to the gravito-inertial force ( $\mathrm{f}=\mathrm{g}-\mathrm{a}$ ). At the same time, by using high-pass filter of angular velocity, the semicircular canals are calculated. After that, afferent signal from the canals and otoliths are compared in the central nervous system (Internal processing). This model combines four freeparameters $\left(\mathrm{k}_{\omega}, \mathrm{k}_{\mathrm{f} \omega}, \mathrm{k}_{\mathrm{f}}\right.$, and $\left.\mathrm{k}_{\mathrm{a}}\right)$. The differences between actual and expected otolith signals were weighted by a parameter $\mathrm{k}_{\mathrm{a}}$ to derive an acceleration estimate. The parameter $\mathrm{k}_{\mathrm{f}}$ was used to rotate the Observer's estimate of the direction of gravity towards reality. The rotation of gravireceptor cue, weighted by a parameter $\mathrm{k}_{\mathrm{f} \omega}$, was used to adjust the Observer's estimate of angular velocity, acting in addition to the $\mathrm{k}_{\omega}$ weighted semicircular canals expectancy error.

\subsection{OKR model}

According to Schweigard \& Mergner, the visual pattern motion in space and time was matched with subject's head movements. It can be calculated by multiple head position with one parameter $(\mathrm{k})$.

In a similar way with Newman ${ }^{(12)}$, Clark $^{(11)}$, and $\operatorname{Oman}^{(13)}$, one negative feedback loop was created which is important to stabilize the image on the retina and the VOR only as a useful addition which compensates for the limited bandwidth of the OKR during high frequency/velocity head rotations. Detail of the model is shown in Figure 5.

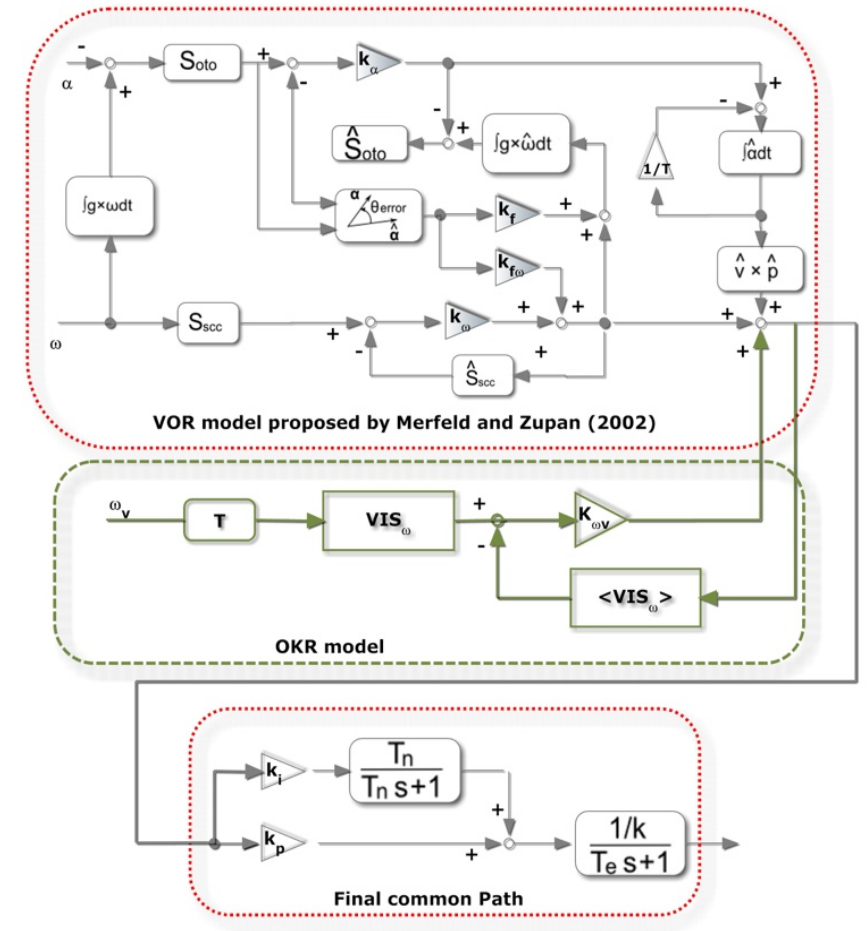

Fig.5. VOR + OKR model developed in this study

In case of driving, it is difficult to measure the input from vision because the target changes time by time. Therefore, we applied technique from Schweigard \& Mergner ${ }^{(10)}$ by using head movement in active condition. The visual information (VS) was calculated based on head movement (HS) following the function: $\mathrm{VS}=k^{*} \mathrm{HS}$. The VS was used as input of our OKR model.

After that, a visual input is processed by visual sensor (VIS) to generate a visual sensory estimate. This estimate is compared to an expected visual sensory evaluated from internal model of visual sensor $(<\mathrm{VIS}>$ ). And then the difference between visual sensory estimate and internal model of the visual sensor is weighted with a residual weighting parameter $\left(\mathrm{K}_{\mathrm{V}}\right)$ and added to the rate of change of estimated state.

\subsection{Final common path}

After calculating the eye movement, the final common path proposed by Robinson ${ }^{(4)}$ was applied. In this part, two parameters $\left(k_{i}\right.$ and $\left.k_{p}\right)$ were used, based on the different types of muscle fibers present in muscles of the eye (Figure 6). 


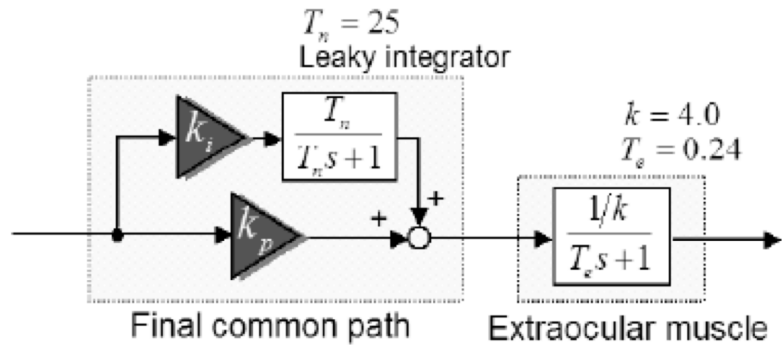

Fig.6. Visual target positions

\subsection{Experimental setup}

In the experiment, a subject was asked to drive following the course on the seat of a driving simulator with six degrees of freedom. The simulator was controlled by CarSim (Mechanical Simulation Co.) which can simulate the dynamic behavior of a vehicle (figure 7). In these experiments, by using MATLAB Simulink (MathWorks) to control CarSim, the seat was moved with a fixed frequency in the vertical and horizontal plane.

In this study, 9 subjects who have driver license participated in the experiment. The participant followed the course in two cases: driving with and without visual stimulus by (trees around the road).

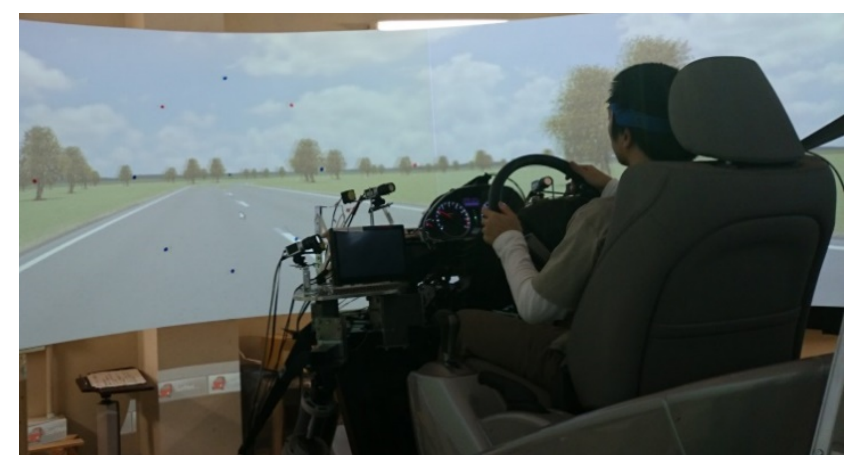

Fig.7. Overview of the experimental setup

The eye movement was collected by using SmartEye Pro (Smart Eye AB) with four cameras on the simulator. This equipment is noninvasive, simple to install, and provides data by using a camera recorder. To collect information on movements of the head, we used a Fastrak electromagnetic tracker (Polhemus Inc.).

\section{- Design course}

We designed a course which includes straight parts, right and left turns, and narrow down. Trees were put around the road with density around $18 \mathrm{~m}$ per tree (Figure 8, Figure 9).

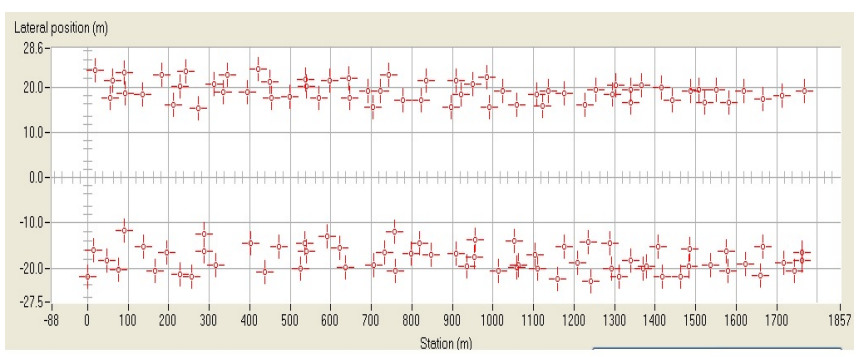

Fig.8. Tree location in the driving course

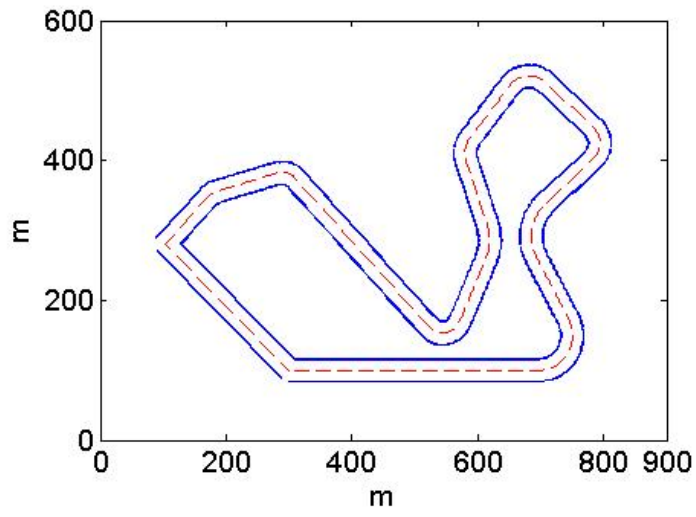

Fig.9. The course used in the experiment

- Seat vibration

In order to create the movement of head and eye when driving, the seat was moved by the control of CarSim by using MATLAB Simulink. The seat was vibrated in two directions: vertical and horizontal. The detailed input for making the vibration is shown in Figure 10.

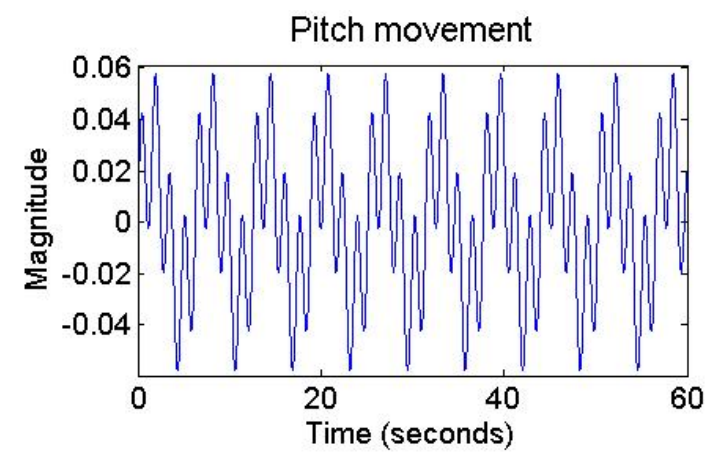

Fig. 10. Input for seat movement

\section{RESULTS AND DISCUSSIONS}

Data from 9 subjects were collected. The subjects were asked to drive and follow the course at a speed between 40 and $60 \mathrm{~km} / \mathrm{h}$. The data of first 4 seconds when subjects drove go straight without visual stimulus was used to identify parameters using parameter identification toolbox proposed by Son et $\mathrm{al}^{(15)}$. The parameter identification was conducted in both models: VOR only and VOR+OKR, separately. 


\subsection{VOR model}

\subsubsection{Without visual stimulus (VS)}

By using VOR model, the results of simulation show good performance with low mean square error. Figure 11 confirmed that the simulation result was good matching in both time responses and frequency response.

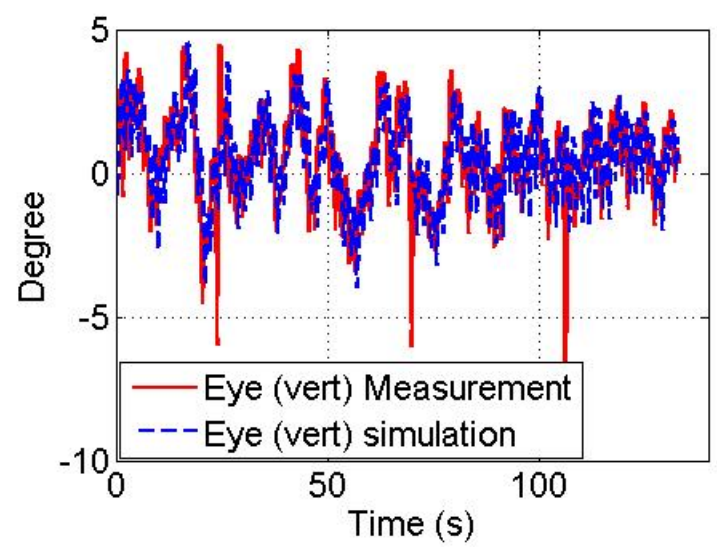

Fig. 11. Eye movement in vertical by VOR without visual stimulus of Subject 1

Table 1 shows the mean square error (MSE) between predict and measurement eye movement of each subjects in both direction: vertical and horizontal. The MSE on vertical direction and horizontal direction increased from 3.1E-04 to 4.3E-03 and from $1.7 \mathrm{E}-03$ to $1.2 \mathrm{E}-02$. The variability of MSE may depend on the driver history and individual characteristic. Due to the limitation of the subject number, we can't see the effect of individual difference statistically in this present paper.

Table 1 MSE* of VOR model without VS of each subjects

\begin{tabular}{|c|c|c|c|c|}
\hline Subjects & Experience & Vertical & Horizon & Total \\
\hline S1 & Regular** & $3.1 \mathrm{E}-04$ & $4.3 \mathrm{E}-03$ & $4.6 \mathrm{E}-03$ \\
\hline S2 & Paper*** & $7.3 \mathrm{E}-04$ & $2.6 \mathrm{E}-03$ & $3.3 \mathrm{E}-03$ \\
\hline S3 & Regular & $3.7 \mathrm{E}-04$ & $6.6 \mathrm{E}-03$ & $7.0 \mathrm{E}-03$ \\
\hline S4 & Regular & $4.3 \mathrm{E}-03$ & $3.5 \mathrm{E}-03$ & $7.8 \mathrm{E}-03$ \\
\hline S5 & Paper & $9.8 \mathrm{E}-04$ & $3.0 \mathrm{E}-03$ & $4.0 \mathrm{E}-03$ \\
\hline S6 & Regular & $1.7 \mathrm{E}-03$ & $4.0 \mathrm{E}-03$ & $5.7 \mathrm{E}-03$ \\
\hline S7 & Regular & $2.0 \mathrm{E}-03$ & $1.2 \mathrm{E}-02$ & $1.4 \mathrm{E}-02$ \\
\hline S8 & Paper & $5.9 \mathrm{E}-04$ & $1.7 \mathrm{E}-03$ & $2.3 \mathrm{E}-03$ \\
\hline S9 & Regular & $2.3 \mathrm{E}-03$ & $3.3 \mathrm{E}-03$ & $5.6 \mathrm{E}-03$ \\
\hline
\end{tabular}

* Unit: $\operatorname{rad}^{\wedge}$

** Regular: the person who drives most frequently

*** Paper: the person who just got driver license or rarely driving

\subsubsection{With visual stimulus}

Base on the VOR model, the eye movement simulation with VS has larger difference than that without VS. The MSE with VS increased from 1.1 times to 2.6 times more compared with that without VS (table 2). This result means that the optic flow by VS increased the MSE by the VOR model. In next step, we added OKR model into VOR model to take the effect of optic flow into account in case of driving with VS.

Table 2 MSE of VOR model without VS and with VS of each subjects

\begin{tabular}{|c|c|c|c|}
\hline Subjects & $\begin{array}{c}\text { VOR } \\
\text { Without VS } \\
{\left[\text { rad }^{\wedge} \text { ] }\right.}\end{array}$ & $\begin{array}{c}\text { VOR } \\
\text { With VS } \\
{\left[\mathbf{r a d}^{\wedge} \text { ] }\right.}\end{array}$ & $\begin{array}{c}\text { Ratio } \\
\text { With/Without }\end{array}$ \\
\hline S1 & $4.6 \mathrm{E}-03$ & $5.0 \mathrm{E}-03$ & 1.1 \\
\hline S2 & $3.3 \mathrm{E}-03$ & $3.6 \mathrm{E}-03$ & 1.2 \\
\hline S3 & $7.0 \mathrm{E}-03$ & $1.8 \mathrm{E}-02$ & 2.6 \\
\hline S4 & $7.8 \mathrm{E}-03$ & $1.3 \mathrm{E}-02$ & 1.7 \\
\hline S5 & $4.0 \mathrm{E}-03$ & $4.4 \mathrm{E}-03$ & 1.1 \\
\hline S6 & $5.7 \mathrm{E}-03$ & $6.2 \mathrm{E}-03$ & 1.1 \\
\hline S7 & $1.4 \mathrm{E}-02$ & $1.6 \mathrm{E}-02$ & 1.1 \\
\hline S8 & $2.3 \mathrm{E}-03$ & $3.4 \mathrm{E}-03$ & 1.5 \\
\hline S9 & $5.6 \mathrm{E}-03$ & $1.0 \mathrm{E}-02$ & 1.8 \\
\hline
\end{tabular}

In addition, when applied VOR model to simulated eye movement in case of with visual stimulus, the time response and frequency response became miss-matching (figure 12).
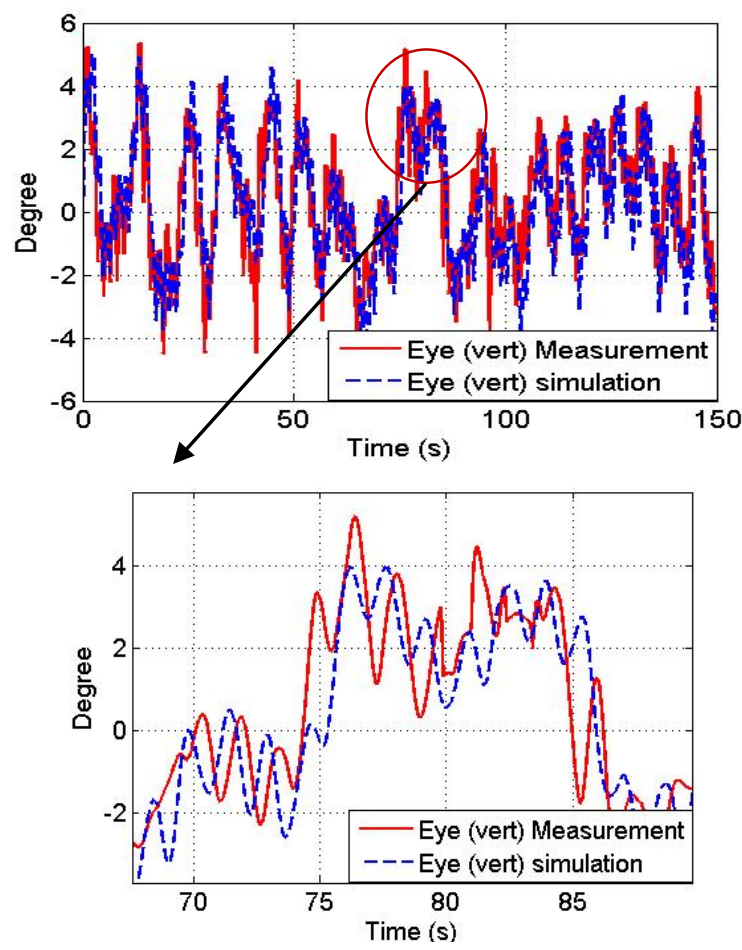

Fig. 12. Eye movement in vertical by VOR with visual stimulus of Subject 1 


\subsection{VOR + OKR model}

\subsubsection{Without visual stimulus}

By the same token in VOR model without visual stimulus, VOR + OKR also showed very good performance with low MSE. The frequency response and time response was good matching (figure 13).

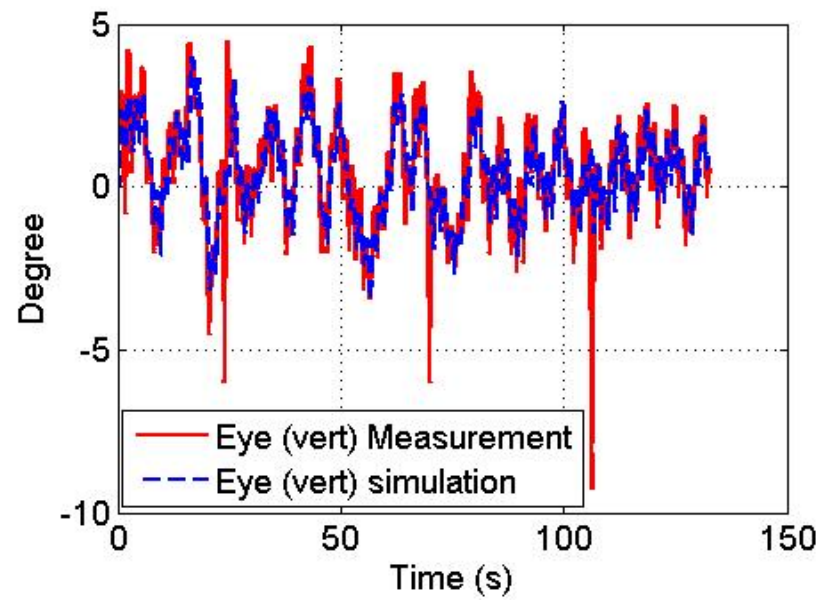

Fig. 13. Eye movement in vertical by VOR $+\mathrm{OKR}$ without visual stimulus of Subject 1

Furthermore, the MSE of VOR+OKR model was even better than MSE of VOR model. As results shows in table 3, the MSE of VOR+OKR model was smaller than that of VOR model. The ratio of $\mathrm{VOR}+\mathrm{OKR} / \mathrm{VOR}$ model increased from 0.3 times to 1.0 times.

Table 3 MSE of VOR model and VOR+OKR model without VS of each subjects

\begin{tabular}{|c|c|c|c|}
\hline Subjects & $\begin{array}{c}\text { VOR } \\
\text { Without VS } \\
\text { [rad }^{\wedge} \text { ] }\end{array}$ & $\begin{array}{c}\text { VOR+OKR } \\
\text { Without VS } \\
\text { [rad }^{\wedge} \text { ] }\end{array}$ & $\begin{array}{c}\text { Ratio of } \\
\text { (VOR+OKR)/VOR }\end{array}$ \\
\hline S1 & $4.6 \mathrm{E}-03$ & $3.3 \mathrm{E}-03$ & 0.7 \\
\hline S2 & $3.3 \mathrm{E}-03$ & $3.3 \mathrm{E}-03$ & 1.0 \\
\hline S3 & $7.0 \mathrm{E}-03$ & $2.4 \mathrm{E}-03$ & 0.3 \\
\hline S4 & $7.8 \mathrm{E}-03$ & $6.0 \mathrm{E}-03$ & 0.8 \\
\hline S5 & $4.0 \mathrm{E}-03$ & $2.5 \mathrm{E}-03$ & 0.6 \\
\hline S6 & $5.7 \mathrm{E}-03$ & $3.7 \mathrm{E}-03$ & 0.7 \\
\hline S7 & $1.4 \mathrm{E}-02$ & $8.8 \mathrm{E}-03$ & 0.6 \\
\hline S8 & $2.3 \mathrm{E}-03$ & $1.2 \mathrm{E}-03$ & 0.5 \\
\hline S9 & $5.6 \mathrm{E}-03$ & $3.6 \mathrm{E}-03$ & 0.6 \\
\hline
\end{tabular}

\subsubsection{With visual stimulus}

Figure 14 shows the eye simulation and eye measurement in case of driving with VS. In contrast with VOR model in case of driving with VS, the results indicated that the time response and frequency response were good matching. Moreover, the results of VOR+OKR model still shown the same way with VOR model with higher MSE in case of with VS (Table 4).
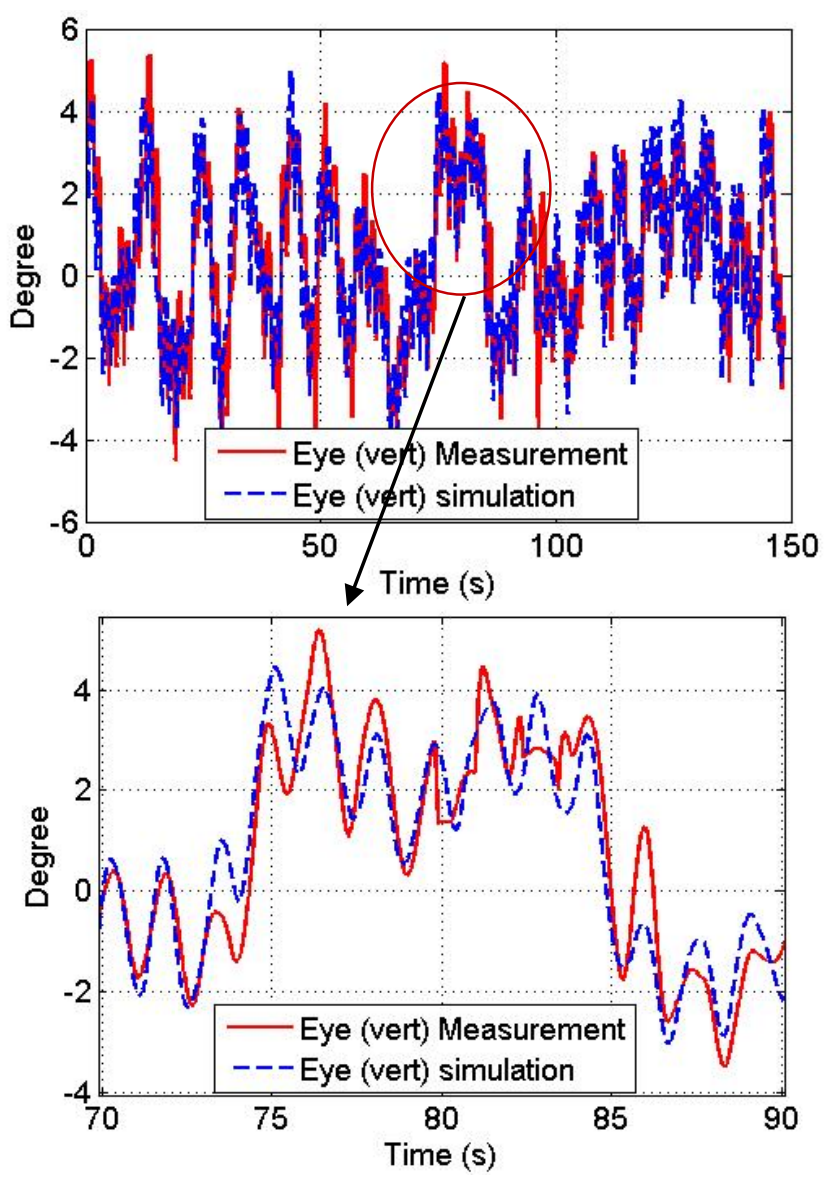

Fig. 14. Eye movement in vertical by VOR $+\mathrm{OKR}$ with visual stimulus of Subject 1

Similarly to the VOR model, the MSE of VOR+OKR model with VS was also bigger than without VS (table 4). The ratio between with and without VS increased from 1.1 to 1.6 times.

Table 4 MSE of VOR+OKR model with and without VS of each subjects

\begin{tabular}{|c|c|c|c|}
\hline Subjects & $\begin{array}{c}\text { VOR+OKR } \\
\text { Without VS } \\
\text { [rad }^{\wedge} \text { ] }\end{array}$ & $\begin{array}{c}\text { VOR+OKR } \\
\text { With VS } \\
\text { [rad }^{\wedge} \text { ] }\end{array}$ & $\begin{array}{c}\text { Ratio } \\
\text { With/Without }\end{array}$ \\
\hline S1 & $3.3 \mathrm{E}-03$ & $3.7 \mathrm{E}-03$ & 1.1 \\
\hline S2 & $3.3 \mathrm{E}-03$ & $4.1 \mathrm{E}-03$ & 1.2 \\
\hline S3 & $2.4 \mathrm{E}-03$ & $3.1 \mathrm{E}-03$ & 1.3 \\
\hline S4 & $6.0 \mathrm{E}-03$ & $9.4 \mathrm{E}-03$ & 1.6 \\
\hline S5 & $2.5 \mathrm{E}-03$ & $3.9 \mathrm{E}-03$ & 1.6 \\
\hline S6 & $3.7 \mathrm{E}-03$ & $4.2 \mathrm{E}-03$ & 1.1 \\
\hline S7 & $8.8 \mathrm{E}-03$ & $9.7 \mathrm{E}-03$ & 1.1 \\
\hline S8 & $1.2 \mathrm{E}-03$ & $1.6 \mathrm{E}-03$ & 1.4 \\
\hline S9 & $3.6 \mathrm{E}-03$ & $5.3 \mathrm{E}-03$ & 1.5 \\
\hline
\end{tabular}




\subsection{Effect of the $O K R$ and the visual stimulus}

Figure 15 shows the average MSE of VOR and VOR + OKR models in case of with and without VS. The VOR $+\mathrm{OKR}$ model shows better performance with lower MSE comparing with VOR model. The VOR+OKR model made the eye simulation became more precise with lower MSE even in case of with visual stimulus.

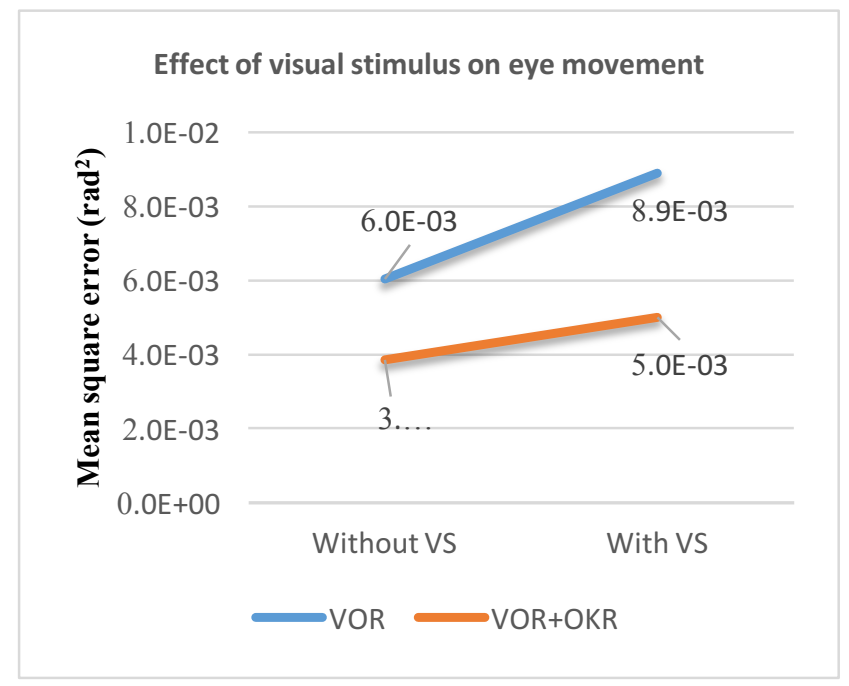

Fig. 15. The average MSE of VOR and VOR+OKR model

Moreover, we performed an analysis of variance (ANOVA) for 9 subjects in the presence and absence of visual stimulus, and with VOR or VOR+OKR model following null hypothesis.

- The results with and without visual stimulus are equal.

- The results of VOR model and VOR+OKR model are equal.

The result shows in table 5

Table 5 ANOVA results

\begin{tabular}{|l|r|r|r|r|r|}
\hline & df & Sum Sq & Mean Sq & F value & $\operatorname{Pr}(>\mathbf{F})$ \\
\hline VS & 1 & $3.5 \mathrm{E}-05$ & $3.5 \mathrm{E}-05$ & 2.47 & 0.1258 \\
\hline Model & 1 & $8.1 \mathrm{E}-05$ & $8.1 \mathrm{E}-05$ & 5.79 & $0.0221^{*}$ \\
\hline VS:Model & 1 & $6.2 \mathrm{E}-06$ & $6.2 \mathrm{E}-06$ & 0.44 & 0.5128 \\
\hline Residuals & 32 & $4.5 \mathrm{E}-04$ & $1.4 \mathrm{E}-05$ & & \\
\hline \multicolumn{5}{|c|}{$*: \mathrm{p}<0.05$} \\
\hline
\end{tabular}

We found that the VOR model and VOR+OKR model was significantly different $(\mathrm{F}=5.79, \mathrm{p}<0.05)$. Although there was tendency of the effects of VS and the interaction between the VS $x$ Model, the ANOVA results indicated that the visual stimulus was not significant and there was no interaction between visual stimulus and VOR and VOR+OKR model. This may due to the limitation of the number of subjects $(\mathrm{N}=9)$. It once again confirmed that $\mathrm{VOR}+\mathrm{OKR}$ show better performance comparing with VOR model.

\section{CONCLUSION}

The model that consists of both VOR and OKR shows better performance than VOR model only in the condition with visual stimulus.

On the other hand, due to the limitation of subjects and only one repeated object in the road (tree) so the effect of visual stimulus was not so clear. In near future, we will try to collect more data by adding more objects around the road to clearly see the effect of VS on eye movement.

\section{REFERENCES}

(1) G. Obinata and S. Tokuda, "Mental Workloads Can Be Objectively Quantified in Real-time Using VOR ( Vestibulo-Ocular Reflex )," International. Federation of Automatic Control, Vol. 17, pp. 15094-15099, (2008). D. M. Merfeld, L. Good, and S. Hospital, "Modeling the vestibulo-ocular reflex of the squirrel monkey during eccentric rotation and roll tilt," pp. 123-134, (1995). L. H. Zupan and D. M. Merfeld, "Neural processing of gravito-inertial cues in humans. IV. Influence of visual rotational cues during roll optokinetic stimuli.," $J$. Neurophysiol., Vol. 89, pp. 390-400, (2003).

D. A. Robinson, "The use of control systems analysis in the neurophysiology of eye movements.," Annu. Rev. Neurosci., Vol. 4, pp. 463-503, (1981).

D. M. Merfeld, L. H. Zupan, J. Vestibular, M. Eye, and E. Infirmary, "Neural Processing of Gravitoinertial Cues in Humans . III . Modeling Tilt and Translation Responses," pp. 819-833, (2002).

(6) D. M. Merfeld and L. H. Zupan, "Neural processing of gravitoinertial cues in humans. III. Modeling tilt and translation responses.," J. Neurophysiol., Vol. 87, pp. 819-833, (2002).

(7) K. Omura, H. Aoki, and G. Obinata, "Objective evaluation of the brake motion by means of passenger's reflex eye movements," International Symposium on Advanced Vehicle Control, Vol. 13, (2014).

(8) G. Obinata, S. Tokuda, K. Fukuda, and H. Hamada, "Quantitative Evaluation of Mental Workload by Using Model of Involuntary Eye Movement," in Engineering Psychology and Cognitive Ergonomics SE - 24, Vol. 5639, D. Harris, Ed. Springer Berlin Heidelberg, pp. 223-232, (2009).

(9) G. Obinata, T. Usui, and N. Shibata, "On-line Method for Evaluating Driver Distraction of Memory-decision Workload Based on Dynamics of Vestibulo-ocular Reflex," Rev. Automot. Eng., Vol. 29, No. 4, pp. 627632, (2008).

(10) G. Schweigart, T. Mergner, I. Evdokimidis, S. Morand, and W. Becker, "Gaze stabilization by optokinetic reflex (OKR) and vestibule-ocular reflex (VOR) during active head rotation in man," Vision Res., Vol. 37, No. 12, pp. 1643-1652, (1997).

(11) M. C. Newman, "A MULTISENSORY OBSERVER 
MODEL FOR HUMAN SPATIAL ORIENTATION PERCEPTION," Master disertation, Department of Aeronautics and Astronautics, Massachusetts Institude of Technology, (2009).

(12) T. K. Clark, M. C. Newman, C. M. Oman, D. M. Merfeld, and L. R. Young, "Modeling human perception of orientation in altered gravity.," Frontiers in Systems Neuroscience, Vol. 9, No. May, p. 68, (2015).

(13) T. K. Clark, M. C. Newman, C. M. Oman, D. M. Merfeld, and L. R. Young, "Human perceptual overestimation of whole body roll tilt in hypergravity.," J Neurophysiol, Vol. 113, No. 7, pp. 2062-2077, (2015).

(14) M. F. Land, "Eye movements and the control of actions in everyday life," Progress in Retinal and Eye Research, Vol. 25, No. 3, pp. 296-324, (2006).

(15) L. A. Son, H. Aoki, H. Hamada, and T. Suzuki, "Parameters Optimization Using Genetic Algorithm Technique for Vestibulo-ocular Reflex model," Future Active Safety Technology Toward zero traffic Accidents, (2015). 